\title{
EIId A
}

\section{Revista Eletrônica de Estudos Integrados em Discurso e Argumentação}

\section{ARGUMENTAÇÃO DE EMOÇÕES NA PUBLICIDADE IMPRESSA}

\section{Giselle Maria Sarti Leal Muniz Alvesi}

Resumo: Este artigo, recorte de uma pesquisa maior, tem como proposta analisar textos de comunicação de massa: dois anúncios publicitários impressos em revistas voltadas para os públicos masculino e feminino - Men's Health e Women's Health, respectivamente. Pretende-se examinar o fenômeno linguístico da patemização, estratégia discursiva cuja finalidade é tocar na afetividade do interlocutor, provocando nele um efeito emocional que o leve à persuasão. A análise está fundamentada, sobretudo, na Teoria Semiolinguística do Discurso, preconizada por Patrick Charaudeau, coadunada com os estudos em Argumentação, à Psicologia das emoções e aos estudos sobre a Linguagem Publicitária.

Palavras-chave: Persuasão. Publicidade. Patemização. Discurso.

\begin{abstract}
This paper, a part of a wider research, aims to analyze mass communication texts: two advertisements from printed magazines oriented to male and female targets, respectively Men's health and Women's health. The objective of the analysis is to examine the linguistic phenomenon of pathemization, a discursive strategy applied with the intention of touching the interlocutor's affections, causing in him an emotional effect towards persuasion. The analysis is based on Semiolinguistics, developed by Patrick Charaudeau, combined with Argumentative Studies, Psychology of Emotions and Advertisement Language Studies.
\end{abstract}

Keywords: Persuasion. Advertising. Pathemization. Discourse.

i Mestre e doutoranda em Letras pela Universidade Federal do Rio de Janeiro (UFRJ). E-mail: gicalealves@hotmail.com. 
EID\&A - Revista Eletrônica de Estudos Integrados em Discurso e Argumentação, Ilhéus, n. 11, jan/jun.2016.

\section{Introdução}

Este artigo, recorte de uma pesquisa mais ampla, tem como proposta analisar dois textos publicitários em anúncios de revistas impressas de grande circulação, voltadas para os públicos masculino e feminino - a Men's Health e Women's Health, respectivamente. Pretende-se examinar o fenômeno linguístico da patemização - processo discursivo-argumentativo pelo qual a emoção pode ser estabelecida.

A patemização constitui-se como estratégia discursiva cuja finalidade é tocar na afetividade do interlocutor, provocando nele um efeito emocional que o leve à persuasão. Trata-se de uma estratégia fundamental no contrato de comunicação publicitário, uma vez que, mediante a referência aos imaginários sociodiscursivos do consumidor em potencial, institui-se uma identificação entre ele e o objeto de anúncio, ratificando-se ou propondo-se a modificação de representações de identidades.

A análise que se propõe está fundamentada, sobretudo, na Teoria Semiolinguística do Discurso coadunada com estudos em Argumentação, Psicologia das emoções e estudos sobre a Linguagem Publicitária. Para justificar a escolha desta temática, devem-se levar em consideração os seguintes aspectos: 1) o emprego da patemização; e 2) o gênero de discurso publicidade impressa em revistas.

Charaudeau afirma que, para que o ato de linguagem aconteça, faz-se necessário que o sujeito comunicante empregue estratégias para entrar em contato com seu interlocutor, para impor sobre ele sua imagem de enunciador, captando, assim, sua atenção. Essas estratégias podem ser de diversas ordens, e seu emprego depende da situação de comunicação na qual o evento enunciativo se inscreve. A escolha do fenômeno da patemização se justifica, então, em função da necessidade de um detalhamento desse tipo de estratégia discursiva de que se pode lançar mão na construção de diferentes cenas enunciativas, dentre as quais se insere o discurso propagandístico.

A escolha do gênero de discurso em questão - a publicidade impressa em revistas - por seu turno, se deve ao fato de estar ele imerso num circuito mercadológico, não tendo um compromisso com a verdade. Nesse sentido, uma argumentação puramente lógica pode não possuir a força persuasiva suficiente para levar o interlocutor ao consumo do objeto de anúncio. Dessa forma, faz-se necessário fundamentar o discurso a partir de uma argumentação das emoções, por meio de estratégias patêmicas. 
EID\&A - Revista Eletrônica de Estudos Integrados em Discurso e Argumentação, Ilhéus, n. 11, jan/jun.2016.

\section{Emoções: delimitando o conceito}

Desde que fundamentada, principalmente, na Teoria Semiolinguística do Discurso, preconizada por Patrick Charaudeau (1992, 2003, 2004, 2007, 2008, 2009, 2010), o foco desta análise está voltado para o estudo de processos discursivos orientados para a construção de cenas enunciativas, em função de determinada intencionalidade comunicativa. Analisa-se, então, um desses processos, a patemização, que consiste no emprego de estratégias linguísticodiscursivas por um dado enunciador, visando a desencadear emoções (efeitos patêmicos) em seu enunciatário. O autor, no entanto, admite que, por ser uma noção central em diferentes mecanismos, "emoção" torna-se um conceito interdisciplinar (CHARAUDEAU, 2010, p.26). Recorre-se, portanto, primeiramente, ao campo da psicologia para delimitá-lo, já que se trata de uma noção central para a análise das peças publicitárias elencadas.

Daniel Goleman (2001) afirma que "emoção se refere a um sentimento e seus pensamentos distintos, estados psicológicos e biológicos, e a uma gama de tendências para agir. Há centenas de emoções, juntamente com suas combinações, variações, mutações e matizes"1.

Quanto às possíveis categorizações das emoções, o autor (GOLEMAN, $2001^{2}$ ) retoma uma polêmica existente entre alguns teóricos, que diz respeito à existência ou não de emoções primárias e secundárias, bem como quais seriam umas e outras. Ele menciona um trabalho pioneiro realizado por Paul Ekman $(1978 ; 2003)^{3}$, de que as expressões faciais de quatro emoções - medo, ira, tristeza e alegria - seriam reconhecidas por culturas de todo o mundo, inclusive por povos intocados pela cultura letrada. Seu caráter universal, então, justificaria que fossem as quatro consideradas como emoções básicas, a partir das quais outros estados psicológicos surgiriam e se combinariam. Nessa mesma perspectiva, advoga-se, neste artigo, a existência de emoções consideradas básicas, passíveis de matização, ou desdobramento.

Goleman $\left(2001^{4}\right)$, na esteira do pensamento de Ekman, admite as emoções “em termos de famílias ou dimensões”, que, por sua vez, teriam um

\footnotetext{
${ }^{1}$ Essa citação foi extraída do Apêndice A da referida obra de Goleman.

${ }^{2}$ Idem à nota 1.

${ }^{3}$ Este pesquisador publicou, em 1978, seu trabalho acerca das expressões faciais - the Facial Action Coding System (FACS) - juntamente com W. Friesen. Em 2003, a obra foi revisada, para a qual J. Hager contribuiu como terceiro autor. Informações extraídas do site <http://www.paulekman.com/paul-ekman/> Acesso em 05/06/2015, às 11 h48.

4 Idem à nota 1.
} 
EID\&A - Revista Eletrônica de Estudos Integrados em Discurso e Argumentação, Ilhéus, n. 11, jan/jun.2016.

núcleo básico, transmutando-se em estados de espírito (que, para ele, são mais contidos e duradouros do que as emoções em si) e temperamentos.

No Quadro 1, em conformidade com a conceituação de Goleman (2001), apresenta-se uma seleção de emoções a serem consideradas na análise do discurso patêmico na publicidade impressa em revistas. Elas estão distribuídas entre emoções básicas e seus possíveis matizes. Ressalte-se, entretanto, que esta lista não esgota as possibilidades de variações e combinações. Na análise dos dados, procurar-se-á verificar em que medida os efeitos patêmicos correspondem a este arrolamento, observando-se, se possível, outras variedades de emoções evocadas a partir das estratégias patêmicas empregadas nos anúncios.

Quadro 1 - Emoções segundo Goleman (2001)

\begin{tabular}{|c|c|c|c|}
\hline \multicolumn{4}{|c|}{ Famílias de emoções } \\
\hline Emoções básicas & & Matizes & \\
\hline Ira & $\begin{array}{l}\text { Fúria } \\
\text { Revolta } \\
\text { Ressentimento } \\
\text { Raiva } \\
\text { Exasperação }\end{array}$ & $\begin{array}{l}\text { Indignação } \\
\text { Vexame } \\
\text { Acrimônia } \\
\text { Animosidade } \\
\text { Aborrecimento }\end{array}$ & $\begin{array}{l}\text { Irritabilidade } \\
\text { Hostilidade } \\
\text { Ódio } \\
\text { Violência }\end{array}$ \\
\hline Tristeza & $\begin{array}{l}\text { Sofrimento } \\
\text { Mágoa } \\
\text { Desânimo } \\
\text { Desalento }\end{array}$ & $\begin{array}{l}\text { Melancolia } \\
\text { Autopiedade } \\
\text { Solidão }\end{array}$ & $\begin{array}{l}\text { Desamparo } \\
\text { Desespero } \\
\text { Depressão }\end{array}$ \\
\hline Medo & $\begin{array}{l}\text { Ansiedade } \\
\text { Apreensão } \\
\text { Nervosismo } \\
\text { Preocupação } \\
\text { Consternação }\end{array}$ & $\begin{array}{l}\text { Cautela } \\
\text { Escrúpulo } \\
\text { Inquietação } \\
\text { Pavor }\end{array}$ & $\begin{array}{l}\text { Susto } \\
\text { Terror } \\
\text { Fobia } \\
\text { Pânico }\end{array}$ \\
\hline Prazer & $\begin{array}{l}\text { Felicidade } \\
\text { Alegria } \\
\text { Alívio } \\
\text { Contentamento } \\
\text { Deleite }\end{array}$ & $\begin{array}{l}\text { Diversão } \\
\text { Orgulho } \\
\text { Prazer sensual } \\
\text { Arrebatamento } \\
\text { Gratificação }\end{array}$ & $\begin{array}{l}\text { Satisfação } \\
\text { Bom humor } \\
\text { Euforia } \\
\text { Exxtase }\end{array}$ \\
\hline Amor & $\begin{array}{l}\text { Aceitação } \\
\text { Amizade } \\
\text { Confiança }\end{array}$ & $\begin{array}{l}\text { Afinidade } \\
\text { Dedicação }\end{array}$ & $\begin{array}{l}\text { Adoração } \\
\text { Paixão }\end{array}$ \\
\hline Surpresa & $\begin{array}{l}\text { Choque } \\
\text { Espanto }\end{array}$ & $\begin{array}{l}\text { Pasmo } \\
\text { Maravilha }\end{array}$ & \\
\hline Nojo & $\begin{array}{l}\text { Desprezo } \\
\text { Desdém }\end{array}$ & $\begin{array}{l}\text { Antipatia } \\
\text { Aversão }\end{array}$ & $\begin{array}{l}\text { Repugnância } \\
\text { Repulsa }\end{array}$ \\
\hline Vergonha & $\begin{array}{l}\text { Culpa } \\
\text { Vexame } \\
\text { Mágoa }\end{array}$ & $\begin{array}{l}\text { Remorso } \\
\text { Humilhação } \\
\text { Arrependimento }\end{array}$ & $\begin{array}{l}\text { Mortificação } \\
\text { Contrição }\end{array}$ \\
\hline
\end{tabular}


Além do campo de conhecimento da psicologia, é importante retomar também os escritos de Aristóteles, uma vez que Charaudeau se refere a conceitos desenvolvidos pelo filósofo, na obra Retórica, situando, assim, sua proposta de análise - à qual esta investigação se filia. O linguista justifica o uso do termo "pathos", em vez de "emoção", com base nos estudos retóricos: "isso me permite, por um lado, inserir a análise do discurso das emoções na filiação da retórica que desde Aristóteles trata os discursos em uma perspectiva de visada e de efeitos" (CHARAUDEAU, 2010, p.35). Nos escritos do filósofo pode-se, igualmente, encontrar, a análise de algumas emoções, ou paixões, como ele denomina, quais sejam: raiva/ calma; amizade/ inimizade; medo/ confiança; vergonha/ cinismo; bondade/ crueldade; compaixão/ indignação; inveja/ emulação.

Comparando-se o seu arrolamento com o de Goleman (2001), evidenciase que coincidem somente as emoções raiva/ ira, medo e vergonha; o tratamento dado às emoções também é distinto, nos dois autores, já que Aristóteles as agrupa em pares opositivos. Nesta análise, consideram-se ambas as categorizações, realizando-se um cruzamento entre elas.

Tendo-se, pois, delimitado o escopo do termo "emoção", segue-se a explicitação da teoria basilar para a análise, a Teoria semiolinguística do discurso, que trata a emoção como um efeito visado. Assume-se, desse modo, que os "sentimentos", os "pensamentos distintos", os "estados psicológicos e biológicos", bem como as "tendências para agir" (cf. Goleman, 2001), não estão propriamente inscritas no discurso, mas, a partir de marcas linguísticas, podem ser suscitados.

\section{A teoria semiolinguística do discurso (TSD)}

O tipo de análise do discurso proposto na TSD é aquele que procura, de fato, contribuir para a melhor compreensão dos fenômenos psicológicos e sociais mediados pela linguagem. Apresentam-se, portanto, alguns conceitos fundamentais dessa perspectiva: a teoria da situação de comunicação, que, por seu turno, remete a uma teoria dos sujeitos da comunicação; a teoria das estratégias de discurso relacionada aos imaginários sociais - na qual se insere o processo de patemização.

$O$ ato de linguagem, sob a ótica da TSD, realiza-se em dois espaços, constituindo-se num duplo circuito. No espaço interno à fala, ou no circuito da 
EID\&A - Revista Eletrônica de Estudos Integrados em Discurso e Argumentação, Ilhéus, n. 11, jan/jun.2016.

fala configurada, ocorre o emprego de marcas linguísticas na construção de enunciados, a partir das normas e padrões de uso do sistema linguístico e do gênero em questão. Por esse circuito, os sujeitos que interagem representam o mundo e são representados discursivamente. No espaço externo à fala, ou no circuito situacional, estão contidas as suas condições de realização.

É esse espaço externo que Charaudeau (2008) considera ao tratar da situação de comunicação, definida por ele como um espaço de troca, no qual um sujeito falante, seu elemento central, "se põe em relação com um parceiro", representando a si mesmos e ao mundo a partir de seus lugares psicossociais, na organização do "real" (CHARAUDEAU, 2008). Logo, há um desdobramento desses sujeitos na enunciação. Pode-se falar de sujeitos marcados socialmente que têm imagens de si projetadas no discurso.

O sujeito comunicante - um ser social - pretende exercer certa influência sobre outro sujeito - também socialmente marcado - que interpretará sua fala. Para alcançar sua intenção comunicativa, esse sujeito comunicante (EUc) constrói, mediante a enunciação, uma imagem de si mesmo - um sujeito enunciador (EUe) -, bem como de seu interlocutor - um sujeito destinatário ideal (TUd). Cabe, então, ao interlocutor - o sujeito interpretante (TUi) - captar essas imagens projetadas, aceitando a proposta do EUe e identificando-se com a imagem do TUd, de modo que os propósitos linguageiros convirjam e a comunicação seja bem sucedida. Para que isso ocorra, então, o EUc transita, na construção e organização dos enunciados, entre o espaço de restrições impostas pelas circunstâncias do evento comunicativo, e o espaço de estratégias, reveladoras da finalidade do seu ato linguageiro, da sua identidade e do seu propósito (CHARAUDEAU, 2007, p.19).

Essa troca linguageira entre dois sujeitos, ou duas instâncias, se insere em um contrato de comunicação - também um conceito basilar da TSD. Esse contrato funcionaria como uma espécie de acordo tácito, acerca dos papéis linguageiros que os sujeitos da interação devem assumir, em função da finalidade da troca. É estabelecido a partir dos conhecimentos partilhados entre os sujeitos em torno das práticas sociais mediadas pela linguagem.

O contrato de comunicação, além de estabelecer restrições situacionais, discursivas e formais à enunciação, prevê, também, um espaço de manobras, onde é permitido ao EUc organizar a matéria linguística na forma de um texto que atenda ao seu propósito comunicativo e produza efeitos de persuasão e de sedução desejados 
EID\&A - Revista Eletrônica de Estudos Integrados em Discurso e Argumentação, Ilhéus, n. 11, jan/jun.2016.

Esse espaço é o responsável por conferir especificidade ao evento enunciativo: é o lugar de onde o EUc se projeta discursivamente, onde revela sua identidade discursiva e sua finalidade comunicativa, por meio do que Charaudeau chama de estratégias de discurso. Não fosse por ele, toda publicidade, por exemplo, seria igual, marcada apenas por aqueles traços recorrentes, que permitem que seja identificada como pertencente ao gênero de discurso publicitário.

As estratégias empregadas no discurso podem ser da ordem da legitimidade, da credibilidade e da captação (CHARAUDEAU, 1995; 2007a; 2009b) $)^{5}$. Esses três aspectos configuram-se como condições para que o ato de linguagem aconteça. Enquanto a legitimidade é a condição que dá o direito à palavra ao EUc, relativa ao reconhecimento de sua identidade social, as condições de credibilidade e de captação dizem respeito à construção de sua identidade discursiva e sua relação com o interlocutor.

Os efeitos de persuasão e de sedução que o EUc deseja produzir no seu interlocutor, mediante o emprego de estratégias de discurso, são identificados por Charaudeau como visadas discursivas. Segundo ele, tais visadas "correspondem a uma intencionalidade psico-sócio-discursiva que determina a expectativa ("enjeu") do ato de linguagem do sujeito falante e por conseguinte da própria troca linguageira” (CHARAUDEAU, 2004, p.5). Elas são atitudes enunciativas engendradas na instância de produção do ato de comunicação, mas, para que o efeito pretendido seja desencadeado, devem ser reconhecidas pela instância de recepção, implicando, portanto, um duplo movimento: a relação de força estabelecida pelo EU em direção ao TU; e a posição ocupada por esse TU em relação ao EU.

O linguista salienta ainda que, dentre as estratégias às quais o EUc pode recorrer, para alcançar a adesão do seu TUi, está "a fabricação de uma imagem de ficção como lugar de identificação do sujeito com um outro, imagem essa que constitui um lugar de projeção do imaginário desse sujeito" (CHARAUDEAU, 2008, p.57). É o que ele denomina imaginários sociodiscursivos, ou seja, referências a um conjunto de valores e crenças socialmente construídas e difundidas que o EUc supõe que o TUd irá reconhecer e com ele se identificar.

\footnotetext{
${ }^{5}$ Esse texto, intitulado Identidade social e identidade discursiva, o fundamento da competência comunicacional, foi publicado na obra O trabalho da tradução, organizado por Márcia Pietroluongo. Foi acessado no site oficial do autor:

<http://www.patrick-charaudeau.com/Identidade-social-e-identidade.html>, em 17/06/2015.
} 
EID\&A - Revista Eletrônica de Estudos Integrados em Discurso e Argumentação, Ilhéus, n. 11, jan/jun.2016.

Tendo-se, assim, apresentado alguns dos conceitos da TSD, segue-se à explicitação da noção de patemização, foco da análise dos dados, enquanto uma das estratégias linguístico-discursivas usadas pelo EUc, no sentido de alcançar o efeito visado em seu ato comunicativo.

\section{A patemização ${ }^{6}$}

O fenômeno linguístico da patemização é definido por Charaudeau (2010, p.34) como "o processo discursivo pelo qual a emoção pode ser estabelecida", sendo tratada a partir de uma perspectiva de efeito. Ele assinala que essa visada patêmica pode ser identificada em ambas as instâncias de produção e de recepção do evento enunciativo, revelando-se em enunciação da expressão patêmica e enunciação da descrição patêmica.

Segundo o estudioso, esse fenômeno pode ser entendido como o emprego de estratégias argumentativas pelo EUc para influenciar o TUi, inserindo em seu projeto de fala um conteúdo emocional, a partir do qual pretende causar um determinado estado qualitativo no interlocutor. Tais estratégias se estruturam a partir de dados - conhecidos ou presumidos pelo EUc - a respeito do imaginário sociodiscursivo do TUi, passíveis de tocar em sua afetividade e movê-lo em direção ao objetivo persuasivo do evento enunciativo - o pathos.

Plantin (2010, p.57-58), no artigo As razões das emoções, explica ser possível argumentar emoções, no sentido de orientar um discurso "em direção à expressão de um afeto", isto é, quando, por esse discurso, se é capaz de justificar "a atribuição de um experienciado a uma pessoa". Tal atribuição, feita a partir do movimento argumentativo, está fundamentada em tópicas de emoção, que ele define como uma espécie de "sistema de mapeamento do real, de coleta de informações e de tratamento do evento com múltiplas finalidades: narrativa, descritiva, argumentativa". É possível afirmar que esse sistema remete à noção de imaginário sociodiscursivo (cf. CHARAUDEAU, 2010), na medida em que abrange o inventário de dados passíveis de emocionar que, por sua vez, estão relacionados às vivências dos sujeitos e aos conjuntos de crenças e normas sociais por ele internalizados.

6 Essa referência ao "pathos" da Retórica aristotélica é realizada apenas nos estudos de Charaudeau. Plantin não se utiliza dos termos "patemização" ou "patêmico", preferindo referir-se ao mesmo processo como "argumentação de emoções". 
EID\&A - Revista Eletrônica de Estudos Integrados em Discurso e Argumentação, Ilhéus, n. 11, jan/jun.2016.

Ambos os autores reconhecem a presença de índices patêmicos ou marcas patêmicas no discurso, que seriam elementos linguísticos orientados para a visada patêmica, sejam eles da ordem da expressão direta, explícita, ou da expressão indireta, implícita e sugestiva.

É possível afirmar que o fenômeno da patemização, ou da argumentação de emoções, é bastante produtivo no gênero propagandístico, em especial, na publicidade comercial. Nota-se que, sem a recorrência a esse recurso, 0 objetivo de transformar o leitor de um anúncio em consumidor efetivo do produto teria pouca ou nenhuma chance de ser alcançado. Para esclarecer, portanto, essa relação entre publicidade e emoção, descreve-se, a seguir, o gênero de discurso propagansístico.

\section{O gênero de discurso propagandístico/ publicitário}

Para tratar do gênero de discurso propagandístico, propriamente dito, cabe um esclarecimento quanto ao conceito de "gênero", na forma como é utilizada por Charaudeau. Sua perspectiva acerca do tema se mostra bastante abrangente e, embora se possa identificar, em certa medida, um diálogo com o conceito bakhtiniano, dele se distingue em alguns aspectos. Em seu artigo Visadas discursivas, gêneros situacionais e construção textual (CHARAUDEAU, 2004), o linguista salienta que uma definição de gêneros de discurso e de tipos de discurso deve considerar o evento comunicativo organizado em diferentes níveis.

Ele reconhece um primeiro nível de organização, o nível dos princípios gerais, formado por quatro princípios de influência que regem a troca linguageira (alteridade, influência, regulação e pertinência). Além deste, destaca o nível dos mecanismos de funcionamento dessa troca, que, por sua vez, compreende os espaços situacional e discursivo da enunciação.

O espaço situacional, ou a situação de comunicação, conforme já foi descrito, é o lugar onde se instituem as restrições advindas das circunstâncias de discurso. Se um conjunto de situações comunicativas partilha as mesmas características, pode-se afirmar que pertencem a um mesmo domínio comunicativo.

O espaço discursivo é o lugar onde se instituem as maneiras de dizer, sendo, portanto, semelhantemente, um espaço de restriçóes, sejam discursivas - referentes aos modos de organização do discurso -, sejam 
EID\&A - Revista Eletrônica de Estudos Integrados em Discurso e Argumentação, Ilhéus, n. 11, jan/jun.2016.

formais - referentes ao emprego obrigatório de maneiras de dizer específicas daquela situação de comunicação.

Em todos esses níveis, de acordo com Charaudeau (2004), é possível fazer referência à noção de gênero. Ele exemplifica essa ideia a partir das especificidades dos títulos de imprensa: inscritos em uma situação de comunicação jornalística, podem ser categorizados como pertencentes ao gênero jornalístico; inseridos, por conseguinte, no domínio midiático, cuja visada predominante é a de informação, pertencem também ao gênero informativo; as restrições discursivas, por seu turno, inscrevem os títulos no gênero anúncio; e as restrições formais, enfim, situam-no no gênero título.

Tomando-se por base a ilustração acima, pode-se considerar que os anúncios publicitários impressos em revistas estão inscritos em uma situação de comunicação publicitária, pertencendo, então ao gênero publicitário. Estão situados no domínio propagandista, cuja visada dominante é a de incitação; pertencem, pois, também, ao gênero propagandista incitativo. De igual modo, as restrições discursivas inserem-nos no gênero anúncio. Já as restrições formais enquadram-nos no gênero anúncio impresso (envolvendo, pois, o layout da página, o apelo visual, a extensão dos enunciados, sua distribuição em blocos, a presença de termos axiológicos, entre outros aspectos).

Observa-se, contudo, que, no artigo $O$ discurso propagandista: uma tipologia, Charaudeau (2010b) categoriza a propaganda não como um gênero, mas como um tipo de discurso, que se concretizaria em diferentes gêneros, tais como o gênero de discurso publicitário, o gênero de discurso promocional (campanhas que promovem o bem estar social) e o gênero de discurso político. Desta forma, entende-se, aqui, que o termo "gênero" pode ser empregado em sentido lato, como no artigo Visadas discursivas, gêneros situacionais e construção textual (CHARAUDEAU, 2004).

Nessa perspectiva, o linguista define o domínio (ou tipologia) propagandista, como um contrato de comunicação marcado pelos seguintes aspectos:

- O "eu" se encontra numa posição de não autoridade e deve, a partir daí, usar uma estratégia de fazer crer, que atribui ao "tu" uma posição de dever crer.

- Este discurso se origina de um ato voluntário proveniente de uma instância de produção, um "eu", que constitui uma fonte [...] coletiva, que é determinada e pode ser imputável do ponto de vista de sua responsabilidade [...]. 
EID\&A - Revista Eletrônica de Estudos Integrados em Discurso e Argumentação, Ilhéus, n. 11, jan/jun.2016.

- Ele tem como alvo uma instância coletiva, o que explica que ele se inscreva sempre num dispositivo de difusão; daí o qualificativo de "propagandista", no seu sentido etimológico de difusão e circulação do discurso no espaço público, junto ao maior número possível de pessoas (propagare).

- Para conseguir o objetivo de fazer crer e colocar a instância de recepção em posição de dever crer, o discurso propagandista se organiza de acordo com um duplo esquema cognitivo, narrativo e argumentativo (CHARAUDEAU, 2010b, p.62-63).

O gênero de discurso publicitário, incluso no domínio propagandista, é definido por Charaudeau (2010, p.64) como um subcontrato, desenvolvido num "dispositivo triangular entre uma instância 'publicitária', uma instância 'concorrência' (a outra marca) e uma instância 'público'”. A instância publicitária se apresenta à instância pública como benfeitora, oferecendo-lhe a realização de seu sonho, por meio de um objeto ideal de busca que é, ao mesmo tempo, o único meio para essa realização. Da relação entre a instância publicitária e a concorrência surge um discurso superlativizado, que justifica a escolha da marca anunciada em detrimento da concorrente.

A expectativa acerca da instância pública, no âmbito individual, é a de que desempenhe o papel de consumidor da publicidade, passando a consumidor efetivo do produto. Enquanto comprador em potencial, o públicoalvo é levado a "dever crer" que tem uma falta a ser por ele preenchida, considerando, para isso, o objeto de anúncio como seu auxiliar na busca que se instaura. Já enquanto consumidor da publicidade, esse público é levado a um "dever apreciar" a encenação que se lhe apresenta e, a partir de um procedimento meta-enunciativo, entender que a instância publicitária necessita de sua conivência.

Segue-se, assim, a análise dos dados, à luz dos apontamentos teóricos apresentados. Observar-se-á a presença da visada patêmica nas duas peças publicitárias selecionadas, examinando-se como e em que medida são empregadas marcas linguístico-discursivas para argumentar emoções. Essa análise será realizada em função do contrato de comunicação publicitário, bem como em função dos papéis sociodiscursivos representados pelos sujeitos do ato comunicativo. 
EID\&A - Revista Eletrônica de Estudos Integrados em Discurso e Argumentação, Ilhéus, n. 11, jan/jun.2016.

\section{A análise}

Como já foi mencionado, este artigo constitui-se em um recorte de uma proposta de análise mais ampla. Sabe-se que a publicidade tem exercido um papel fundamental na disseminação de crenças e valores - imaginários sociodiscursivos - que reforcem a necessidade de consumo. Essa, então, é a principal motivação para a presente pesquisa, que compreende na comparação da publicidade voltada para os públicos masculino e feminino anúncios das revistas impressas Men's Health e Women's Health. Procura-se observar, como as identidades dos gêneros masculino e feminino são representadas nesses textos, a partir dos efeitos patêmicos neles engendrados, inseridas nesse contrato de comunicação específico, em que os sujeitos sociais assumem papéis discursivos também específicos. São identificadas, nos anúncios, marcas patêmicas diretas e indiretas, que remetem ao arrolamento de emoções apresentado na seção (1) e que sugerem a idealização de um determinado tipo de sujeito destinatário para cada um.

Como amostra dessa proposta, selecionaram-se duas peças publicitárias. A primeira (cf. Anexo, figura A), foi extraída da revista Women's Health (julho/ 2012); a segunda (cf. Anexo, figura B), da revista Men's Health (abril/ 2012). Ambas são de publicação mensal, na versão impressa. Os dois textos apresentam a imagem da mulher como elemento central, ou seja, numa perspectiva de cena enunciativa, a mulher é a protagonista de ambos, vista, contudo, sob prismas bastante distintos.

No texto (A), voltado para o público feminino (cf. Anexo), o produto anunciado é o Antitranspirante Dove, em suas versões spray e roll on, conforme imagem no canto direito inferior. A imagem feminina se mostra sorridente, de braços abertos, sugerindo um abraço, gesto que reitera a proposta do enunciado principal: "Abrace a vida com axilas maravilhosas, agora com mais vitamina E".

Desde que a temática do anúncio gire em torno da beleza das axilas, o gesto da mulher pode ser interpretado em função da liberdade de mostrá-las sem preocupações, uma vez que estão maravilhosas, num movimento argumentativo que pode ser reconstruído da seguinte forma: Se você, mulher, quer abraçar a vida, então tem de ter axilas maravilhosas. Se você quer ter axilas maravilhosas, então deve usar o Antitranspirante Dove com mais vitamina $\mathrm{E}$. 
EID\&A - Revista Eletrônica de Estudos Integrados em Discurso e Argumentação, Ilhéus, n. 11, jan/jun.2016.

No que tange ao apelo às emoções da interlocutora, é possível observar que o EUe se coloca numa posição de benfeitor, ao apresentar à leitora um produto, cuja nova fórmula - com "o dobro de vitamina E" - deixará suas "axilas suaves, macias e bonitas", permitindo-lhe, assim, "abraçar a vida", sem medo de levantar os braços e ser constrangida com uma aparência indesejável dessa parte de seu corpo.

É interessante notar que, como a identidade da mulher é construída em função da rejeição do aspecto natural do seu corpo e em função da impressão a causar no outro, o uso do produto se justifica pelo fato de que ela poderá abraçar a vida, pois suas axilas estarão "maravilhosas". Cabe mencionar, aqui, o reforço de uma identidade feminina que tem o corpo como elemento central para a conquista da felicidade. Trata-se de um estereótipo que vai ao encontro da ideia da mulher que se submete a qualquer procedimento, com vistas a melhorar a aparência física, de modo a agradar o homem e evitar a rejeição. Ter "axilas maravilhosas" seria, então, uma expressão patemizante, no sentido de suscitar não somente o prazer estético, como também o medo da rejeição, caso o TUd - a leitora de Women's Health - não se enquadre nesse estereótipo. A figura do homem se faz presente, mesmo na ausência, como uma referência externa ao anúncio, como aquele a quem a protagonista mostrará "suas axilas maravilhosas".

O termo "abraçar a vida" pode ser entendido como entregar-se inteiramente aos abraços, aos encontros que a vida proporciona, e isso só é possível se a mulher não tiver vergonha de mostrar as axilas ao estender os braços. O produto, desta forma, é colocado como auxiliar nessa busca por "axilas maravilhosas", o que ela não conseguiria de forma natural. A leitora é convidada, então, a se projetar na imagem retratada no anúncio, sendo incitado nela o desejo de ter axilas tão maravilhosas, que lhe proporcionem a liberdade, a felicidade e o prazer estampados naquele rosto. A tópica do prazer é reforçada pela cor branca - representativa de segurança e paz - e pelo uso de termos sugestivamente patemizantes, tais como:

- "abrace", que evoca a afetividade, no sentido de que é uma expressão de afeto, seja amor, amizade, carinho, cuidado, proteção, segurança, conquista.

- "maravilhosas", "suaves", "macias", "bonitas" e "lindas", atributos que remetem ao prazer estético, à satisfação, à autoestima elevada. 
EID\&A - Revista Eletrônica de Estudos Integrados em Discurso e Argumentação, Ilhéus, n. 11, jan/jun.2016.

- "Vá em frente", um enunciado que designa uma espécie de lugar comum comportamental (cf. PLANTIN, 2010), e que remete à ideia de encorajamento.

No texto (B), dirigido ao público masculino (cf. Anexo), são anunciados suplementos proteicos da marca Max Titanium, artigos bastante utilizados por pessoas que praticam musculação, fisiculturistas, bodybuilders e modelos fitness - como é o caso da mulher retratada, a celebridade Gracyanne Barbosa. Ela se mostra séria, com os braços erguidos, mãos entrelaçadas nos cabelos, numa postura sensualizada.

Seu físico de musculatura rígida e definida é colocado em destaque pela roupa com que está vestida - shorts e top colados ao corpo -, deixando grande parte dele exposto; observa-se, também, o jogo de luz e sombra que ressalta o tônus de seus braços, abdômen e coxas, enquadrados num padrão fitness bastante desejado tanto por homens quanto por mulheres leitores do tipo de revista em questão. Logo, esse destaque se coaduna com a temática do anúncio, referente à suplementação proteica, que auxilia no ganho e na definição de massa muscular.

Pode-se afirmar que o enunciado central - "Qual é a sua meta?" - se mostra sutilmente ambíguo, podendo o termo "meta" ser interpretado de duas formas. Pode evocar uma representação do gênero masculino como aquele a quem é atribuída a força física, patente pela protuberância dos músculos; dessa forma, a "meta" pode se referir ao objetivo de ter músculos como os de Gracyanne, uma celebridade reconhecida por esse atributo "masculinizado". Pode-se inferir um tom desafiador, permeado por um certo machismo, na forma como o EUe interpela o TUd: se até uma mulher consegue um corpo esculpido, então, você, homem, tem que conseguir, por ser superior à mulher; logo, compre o produto.

Por outro lado, considerando-se a sensualidade com que a modelo se apresenta na imagem, sendo um anúncio voltado para homens, procura-se despertar o desejo sexual em relação a ela. Desse modo, a "meta" a ser alcançada também pode fazer referência ao objetivo de conquistar uma mulher como Gracyanne, evocando, assim, uma representação de identidade masculina como aquela do conquistador. Mais uma vez, observa-se a presença a figura do homem dominador, superior à mulher, mesmo que linguisticamente ele esteja ausente. 
EID\&A - Revista Eletrônica de Estudos Integrados em Discurso e Argumentação, Ilhéus, n. 11, jan/jun.2016.

O apelo às emoções do interlocutor é construído, então, a partir dessa ideia de conquista, tanto no enunciado central, reforçado pela forma interrogativa, quanto na imagem da modelo. O movimento argumentativo pode ser reconstruído da seguinte forma: Você, homem, tem de ter uma meta (o ganho de massa muscular) e você só a alcançará se consumir os suplementos proteicos Max Titanium.

O leitor é convidado a responder à pergunta feita, projetando-se para a cena enunciativa, em que se depara com a imagem de Gracyanne Barbosa, como fonte motivadora. Os efeitos patêmicos que se pretende desencadear são o de prazer, seja ele estético, seja ele sensual, e o de poder. Esses efeitos são corroborados pela cor preta - que evoca imaginários sociodiscursivos que remetem à sensualidade e do poder. É essa a cor predominante tanto como pano de fundo, quanto na roupa de Gracyanne. Seu olhar penetrante, seu semblante sério, sua postura, explicitamente dramatizada, numa atitude sedutora, reforçam as tópicas do prazer e do poder (de sedução). Observa-se, ainda, a presença de termos sugestivamente patemizantes que, semelhantemente, ratificam a intenção do EUc em gerar esses efeitos patêmicos no leitor do anúncio:

- "Máximo", adjetivo superlativizador, que remete a um limite de qualidade que não se pode ultrapassar, evocando, assim, a ideia de segurança e confiabilidade.

- "Desempenho" e "resultado", substantivos que se referem aos benefícios oferecidos pelo produto, reforçando a ideia de poder.

Afirmar que os suplementos Max Titanium oferecem "máximo desempenho" e "máximo resultado", coloca o produto no topo de uma escala, estando abaixo dele, outros produtos concorrentes, que podem ter média, mínima ou, até, nenhuma eficácia. Logo, trata-se de um produto seguro, confiável. Se o leitor, então, se torna consumidor efetivo do produto, será posicionado, igualmente, no topo de uma escala, em termos de desempenho em seus treinos e resultados no ganho de massa muscular, ou seja, não haverá ninguém como ele.

Comparando-se os dois anúncios, é possível observar que um contraste é estabelecido, no que tange às representações do gênero feminino. No primeiro anúncio, extraído da Women's Health, a ideia de sensualidade é colocada de lado, o que fica evidente pela vestimenta pueril da protagonista: um vestido branco de modelo um pouco até infantilizado, sem destaque para 
EID\&A - Revista Eletrônica de Estudos Integrados em Discurso e Argumentação, Ilhéus, n. 11, jan/jun.2016.

seios ou qualquer outra parte tipicamente "provocativa" do corpo da mulher. Pode-se afirmar que a cor e o modelo do vestido recuperam uma certa pureza da imagem feminina, focalizando-se sua liberdade, sua alegria por estar bem consigo mesma.

O segundo anúncio, por seu turno, possui um teor mais "sombrio", mais noturno, apresentando-se a imagem feminina com traços fortes, sérios, sem a fragilidade presente no primeiro. A cor e o modelo da roupa aludem a uma representação da sexualidade feminina, que, com várias partes do corpo à mostra, é colocada como objeto de desejo para o TUd - o leitor da Men's Health. Embora ambas as mulheres estejam de braços erguidos, o sentido desse gesto pretende um efeito patêmico completamente diferente. Enquanto a imagem "mulher de branco" sugere um ideal de liberdade, a imagem da "mulher de preto" parece sugerir uma submissão sexual ante a figura masculina. Pode-se evidenciar, entretanto, em ambas as cenas, a presença subliminar da figura masculina, uma vez que o corpo da mulher seja considerado um instrumento para agradar o homem; em outras palavras, a mulher cuida do corpo, seja por meio de cosméticos, seja esculpindo-o na academia, para exibi-lo ao homem e nele despertar o desejo de possui-la, alcançando, assim, a plenitude da felicidade. Nota-se uma relação assimétrica dos estereótipos de gênero, em que o homem encontra-se em posição superior à mulher.

Por fim, vale destacar que em ambos não foram empregados termos explicitamente patemizantes, mas apenas termos de designação indireta, ou sugestivamente patemizantes. Observe-se, todavia, que, no anúncio para o público feminino, há enunciados mais extensos e uma quantidade maior de termos indiretos de emoção. Já no anúncio para o público masculino, o apelo visual se sobrepõe ao verbal. Em termos de marcas linguísticas patemizantes, pode-se depreender que a carga emocional é maior no anúncio para mulheres, do que para homens, o que parece remeter, também, aos imaginários sociodiscursivos que sugerem uma representação feminina mais subjetiva e propensa ao apelo emocional, enquanto a masculina seria mais objetiva e, consequentemente, mais racional. 
EID\&A - Revista Eletrônica de Estudos Integrados em Discurso e Argumentação, Ilhéus, n. 11, jan/jun.2016.

\section{Considerações finais}

Buscou-se analisar, sob uma perspectiva discursiva, textos publicitários em anúncios impressos em revistas dirigidas aos públicos masculino e feminino, observando-se a ocorrência do fenômeno da patemização.

Por meio da análise qualitativa das duas peças publicitárias, pode-se verificar a presença do apelo às emoções, configurado diferentemente para o público feminino e para o masculino. Embora a tópica do prazer estético esteja presente em ambos, no anúncio para o target feminino, observa-se a orientação a um prazer voltado para a liberdade, e autossatisfação, numa relação da mulher com ela mesma, estando a figura masculina implicitamente presente, com menor destaque. Já no anúncio para o target masculino, observa-se a incitação ao prazer sexual, numa relação mais explícita do homem com a mulher.

A patemização se mostra, assim, como uma estratégia argumentativa cuja função principal parece ser preencher uma lacuna no discurso publicitário, que diz respeito à não obrigatoriedade desse contrato com a veracidade, senão com a verossimilhança. Na falta de argumentos lógicos que convençam o interlocutor à compra dos produtos anunciados, devido à presença de muitas opções no mercado, busca-se uma argumentação das emoções, de modo a tocar na afetividade do consumidor em potencial. Podese afirmar, com isso, que o fenômeno da patemização constituir-se-ia como base para a construção do texto pertencente ao gênero textual publicitário.

Ainda que seja apenas uma amostra de uma pesquisa mais ampla, não se pode negar sua importância, no sentido de elucidar aspectos linguísticodiscursivos implicados na construção da mensagem publicitária, bem como lançar um olhar mais detalhado no delineamento da visada patêmica, que ainda necessita de muitos esclarecimentos. Sugere-se, assim, que outros estudos sejam realizados, com vistas a identificar a patemização em outros gêneros, ou, até mesmo, em outras modalidades da própria publicidade. 
EID\&A - Revista Eletrônica de Estudos Integrados em Discurso e Argumentação, Ilhéus, n. 11, jan/jun.2016.

\section{Referências}

AMOSSY, Ruth. Imagens de si no discurso. São Paulo: Contexto, 2008.

CARVALHO, Neli de. Publicidade: a linguagem da sedução. São Paulo: Ática, 2007.

CHARAUDEAU, Patrick. Ce que communiquer veut dire. Revue des Sciences humaines, n.51, Juin, 1995.

. Uma análise semiolinguística do texto e do discurso. In: PAULIUKONIS, Maria Aparecida Lino; GAVAZZI, Sigrid (Org.). Da língua ao discurso: reflexões para o ensino. Rio de Janeiro: Lucerna, 2007. p.11-29.

. Analyse de discours et communication. L'un dans l'autre ou l'autre dans l'un?. Revue Semen, Besançon, n. 23, 2007.

. Pathos e discurso politico. In: MACHADO, Ida Lúcia; MENEZES, William; MENDES, Emília (Org.). Emoções no Discurso, v.1. Rio de Janeiro: Lucerna, 2007. p.240-251.

. Linguagem e discurso: modos de organização. São Paulo: Contexto, 2008.

. O Discurso das mídias. São Paulo: Contexto, 2009.

. A patemização na televisão como estratégia de autenticidade. In: MACHADO, Ida Lúcia; MENDES, Emília (Org.). Emoções no Discurso, v.2. Campinas: Mercado das Letras, 2010. p. 23-56.

- O discurso propagandista : uma tipologia. In: MACHADO, Ida Lucia; MELLO, Renato (Org.). Análises do Discurso Hoje, v. 3. Rio de Janeiro: Nova Fronteira, 2010. p.57-78.

GOLEMAN, Daniel. Inteligência emocional: a teoria revolucionária que define o que é ser inteligente. Rio de Janeiro: Objetiva, 2001.

PLANTIN, Christian. La construction rhétorique des émotions. In: RIGOTTI, E (Ed.). Rhetoric and argumentation. Proceedings of the 1997 IADA International conference. Lugano, 1997. p. 203-219.

. Les raisons des emotions. In: BONDI, M (Ed.). Forms of argumentative discourse / Per un'analisi linguistica dell'argomentare. Bologne: CLUEB, 1998a. p. 350.

. Arguing emotions. In: VAN EEMEREN F. H. et al. Proceedings of the Fourth International Conference of the International Society for the Study of Argumentation. 1998. p. 631-638. 
EID\&A - Revista Eletrônica de Estudos Integrados em Discurso e Argumentação, llhéus, n. 11, jan/jun.2016.

. As razões das emoções. In: MACHADO, Ida Lúcia; MENDES, Emília (Org.). Emoções no Discurso, v.2. Campinas: Mercado das Letras, 2010. p. 57-80.

\section{Anexo}

A

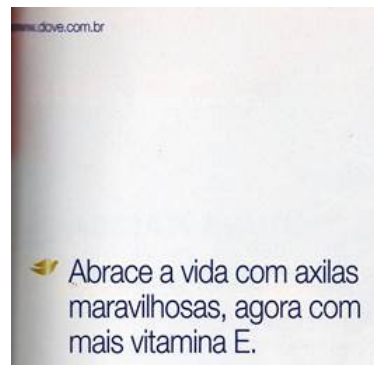

A xy
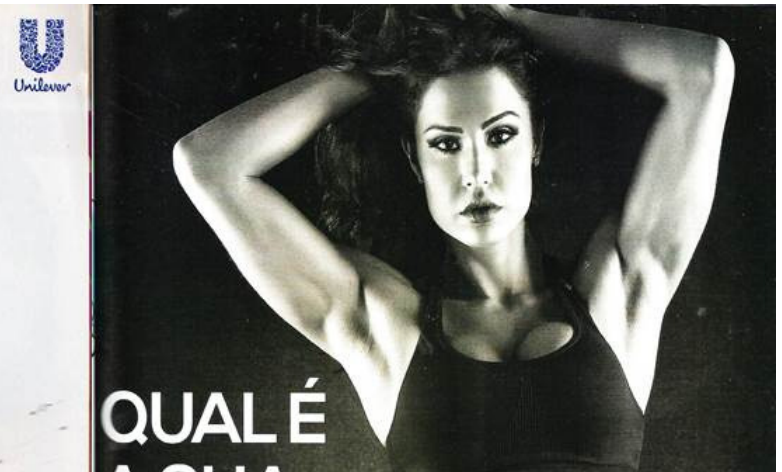
A SUA

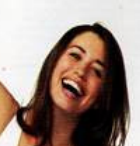

(2)
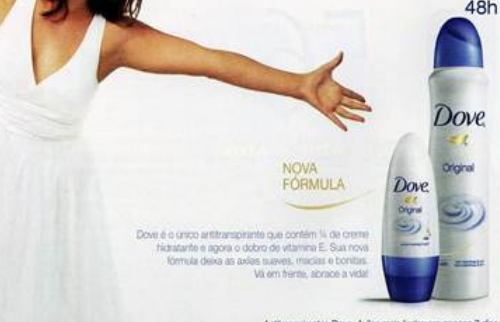
META?

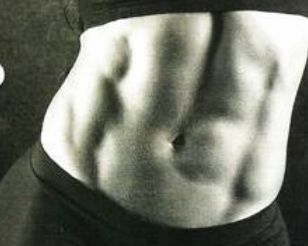

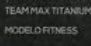

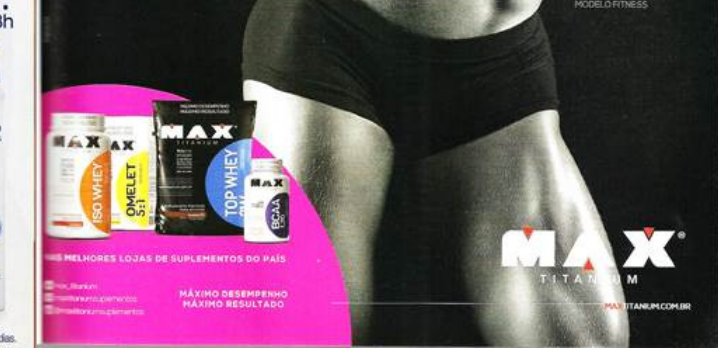

Fonte: Women's Health (julho/2012) e Men's Health (abril/ 2014)

B 